\section{PTH-159 GROUP EDUCATION IS AS EFFECTIVE AS ONE-TO-ONE SESSIONS WHEN ADMINISTERING THE LOW FODMAP DIET IN FUNCTIONAL BOWEL DISORDERS}

doi:10.1136/gutjnl-2013-304907.646

1,2T Joyce, ${ }^{1,2} \mathrm{H}$ M Staudacher, ${ }^{2} \mathrm{~K}$ Whelan, ${ }^{2,3, *} \mathrm{P} \mathrm{M}$ Irving, ${ }^{1,2},{ }^{3} \mathrm{M} \mathrm{C}$ Lomer. ${ }^{1}$ Dietetics, Guy's and St Thomas' NHS Foundation Trust; 'Diabetes and Nutritional Sciences, King's College London; 'Gastroenterology, Guy's and St Thomas' NHS Foundation Trust, London, UK

Introduction The low FODMAP diet is an effective intervention for people with functional bowel disorders (FBD). It has been introduced successfully to the UK with $>250$ dietitians trained in its implementation. However, teaching patients about the diet is labour intensive; initial appointments typically last one hour. Given the prevalence of $\mathrm{FBD}$, this represents a significant obstacle to widespread use. Group education sessions (GS) are a possible solution and are effective for dietary interventions in other disorders (e.g. diabetes, obesity), although their effectiveness has not been established for the low FODMAP diet. We aimed to compare the effectiveness of GS with one-to-one sessions (OS).

Methods Patients referred in 2011-12 with FBD were pre-assessed by telephone to confirm suitability for GS. Those with atypical symptoms or with other medical or nutritional concerns were excluded. Suitable patients were offered the choice of GS or OS. Up to 12 patients were seen in each GS lasting $1.5 \mathrm{~h}$ and were then followed up 6-10 weeks later in a 1h GS. Patients seen in OS had an initial $1 \mathrm{~h}$ appointment and then a $0.33 \mathrm{~h}$ follow-up, 6-10 weeks later. Effectiveness of the diet was compared in OS and GS. Symptoms were measured using the gastrointestinal symptom rating scale at baseline and follow-up and clinical effectiveness through the global symptom question (GSQ). Comparisons were made using the $\chi^{2}$ test. Acceptability of GS sessions was also assessed.

Results Data from 168 patients attending GS (70\% female, mean age $39 y)$ were compared with 50 patients attending OS $(60 \%$ female, mean age 47y). Positive responses to the GSQ 'do you currently have satisfactory relief of your gut symptoms' improved from $30 / 155(19 \%)$ at baseline to $71 / 146(49 \%)$ in the GS $(\mathrm{P}<0.001)$ and from $2 / 45(4 \%)$ to $23 / 44(52 \%)$ in the OS patients ( $\mathrm{P}=0.016)$ Proportion of those with adequate control at follow up was not significantly different between OS and GS (P = 0.895). At follow up, $94 \%$ of GS patients reported adherence to the diet $>50 \%$ of the time. Most of the GS patients felt length of the sessions (95\%), content $(93 \%)$ and balance between education and patient involvement (95\%) were 'just right'. In retrospect, 39\% would have preferred OS, with the remainder preferring GS or expressing no preference.

Conclusion GS are an effective medium for instructing patients in the implementation of the low FODMAP diet. Whilst a significant minority attending GS would have preferred OS, there are several possible advantages to GS including peer-support and sharing of experiences. Most importantly, GS allow increased capacity and shorter waiting times.

Disclosure of Interest None Declared.

\section{PTH-160 STRAIGHT TO TEST COLONOSCOPIES FOR SUSPECTED COLORECTAL MALIGNANCY- 5 YEAR FOLLOWUP OF PATIENTS WITH NORMAL COLONOSCOPIES WHO WERE DISCHARGED BACK TO GP}

doi:10.1136/gutjnl-2013-304907.647

\footnotetext{
1."P Mundre, 'J Eaden, 'M Denyer, 'V Subramanian. 'Gastroenterology, St James s University Hospital, Leeds, UK
}

Introduction Straight To Test (STT)services has been adopted by hospitals throughout the UK to improve the efficiency of pathways for early cancer diagnosis. Our previous results suggest that STT colonoscopies for suspected colorectal malignancy are feasible, safe and accurate ${ }^{1}$. There has been no studies however on the long term (5 years or greater) outcomes after a normal colonoscopy in these patients. It is unclear if it is safe to discharge them back to primary care. We aimed to look at the 5 year outcomes after a negative STT colonoscopy for patient s referred for suspected colorectal malignancy in 2007

Methods In 2008 we conducted a retrospective study of all straight to test colonoscopies (Jan 2007 to Dec 2007) in Seacroft Hospital, Leeds ${ }^{1}$. Of the 195 colonoscopies (150 for rectal bleeding and change in bowel habits and 45 for iron deficiency anaemia), 104 were either normal or had insignificant findings and were discharged back to GPs without hospital follow-up. We looked at hospital records of all these patients in Dec 2012 (5 years after their index procedure) for further hospital contact, investigations or other diagnosis. Data was collected from the hospitals electronic patient record (patient pathway management system or PPM which records all secondary care hospital episodes in West Yorkshire) and the results server. All secondary care contacts and investigations by these patients would have been captured by PPM and results server.

Results Of the 104 included patients, we collected follow-up data on 96 (In 8 data could not be traced). 76 of these were never referred back to secondary care. 20 were referred back with various symptoms, 6 of whom had normal investigations, 9 had benign gastrointestinal disease and 5 developed cancers as detailed in table below.

\section{Abstract PTH-160 Table 1}

\begin{tabular}{lll}
\hline Site of Cancer & $\begin{array}{l}\text { Time to diagnose after index } \\
\text { colonoscopy }\end{array}$ & Main presentation \\
\hline Metastatic carcinoid, unknown primary & 06 months & Abdominal pain \\
Lung & 38 months & Cough \\
Breast & 38 months & Weight loss \\
Metastatic pancreatic cancer & 47 months & Weight loss \\
Colon (Dukes B) & 68 months & Weight loss \\
\hline
\end{tabular}

Conclusion Only 1 patient developed colorectal malignancy on follow-up, but presented more than 5 years after the index colonoscopy with weight loss and but had a normal CT abdomen in the interim. 4 other had other malignancies with weight loss as the presenting feature in $50 \%$. Patients who undergo STT colonoscopies for suspected colorectal malignancy can be discharged back to the GP with confidence by the endoscopist without follow-up in secondary care, but patients need to be warned to seek urgent help if losing weight.

Disclosure of Interest None Declared.

\section{REFERENCE}

1. THE LEEDS EXPERIENCE OF THE STRAIGHT TO TEST PATHWAY F. A. Butt*(1), P. Mundre (2), G. G. Robins (2), M. Chadwick (2), M. E. Denyer (2), (1) (2) Gastroenterology, St James's Hospital, Leeds, United Kingdom

\section{PTH-161 OUTCOME OF INVESTIGATIONS PERFORMED FOLLOWING A POSITIVE FAECAL CALPROTECTIN: A NINE MONTH PILOT STUDY FROM A DISTRICT GENERAL HOSPITAL}

doi:10.1136/gutjnl-2013-304907.648

1.*P T Rajasekhar, 'R Bevan, ' $\mathrm{C}$ Parker, ${ }^{1} \mathrm{C}$ Rees, ' $\mathrm{S}$ Panter. 'Gastroenterology, South Tyneside District Hospital, South Shields, UK

Introduction Faecal calprotectin (FCP) is a neutrophil degradation product used to detect inflammation within the gastrointestinal tract. It can aid differentiation of inflammatory bowel disease (IBD) from functional disorders and in the monitoring of IBD. We evaluated the outcome of investigations performed following a positive FCP at South Tyneside District Hospital.

Methods All positive FCP results (values $>60 \mathrm{microg} / \mathrm{g}$ ) were identified (1/1/12 and 30/9/12). Endoscopy and radiological results were 
Abstract PTH-161 Table 1

\begin{tabular}{|c|c|c|c|c|c|c|c|c|c|}
\hline Group & $\begin{array}{l}\text { Known } \\
\text { IBD (\%) }\end{array}$ & $\begin{array}{c}\text { New } \\
\text { IBD (\%) }\end{array}$ & PUD (\%) & NSI (\%) & Cancer (\%) & $\begin{array}{c}\text { CRA } \\
(\%)\end{array}$ & Coeliac (\%) & Unknown (\%) & Other (\%) \\
\hline Age $<55+$ FCP 60-100 $(n=15)$ & $\begin{array}{c}\text { AB4 } \\
(26.7)\end{array}$ & $\begin{array}{l}A B 0 \\
(0.0)\end{array}$ & $\begin{array}{l}\text { ABO } \\
(0.0)\end{array}$ & $\begin{array}{c}\text { AB2 } \\
(13.3)\end{array}$ & $\begin{array}{l}\text { ABO } \\
(0.0)\end{array}$ & $\begin{array}{l}A B 0 \\
(0.0)\end{array}$ & $\begin{array}{l}\text { ABO } \\
(0.0)\end{array}$ & $\begin{array}{l}A B 1 \\
(6.7)\end{array}$ & $\begin{array}{c}\text { AB8 } \\
(53.3)\end{array}$ \\
\hline Age $<55+$ FCP $>100(n=68)$ & $\begin{array}{l}\text { AB39 } \\
(57.4)\end{array}$ & $\begin{array}{l}\text { AB6 } \\
(8.8)\end{array}$ & $\begin{array}{l}\text { AB2 } \\
(2.9)\end{array}$ & $\begin{array}{l}\text { AB3 } \\
(4.4)\end{array}$ & $\begin{array}{l}\text { ABO } \\
(0.0)\end{array}$ & $\begin{array}{l}\text { ABO } \\
(0.0)\end{array}$ & $\begin{array}{l}\text { AB1 } \\
(1.5)\end{array}$ & $\begin{array}{l}\text { AB4 } \\
(5.9)\end{array}$ & $\begin{array}{l}\text { AB13 } \\
(19.1)\end{array}$ \\
\hline Age $>55+$ FCP 60-100 $(n=11)$ & $\begin{array}{c}\text { AB3 } \\
(27.3)\end{array}$ & $\begin{array}{l}\mathrm{ABO} \\
(0.0)\end{array}$ & $\begin{array}{l}A B 0 \\
(0.0)\end{array}$ & $\begin{array}{l}A B 0 \\
(0.0)\end{array}$ & $\begin{array}{l}A B 0 \\
(0.0)\end{array}$ & $\begin{array}{l}\text { AB1 } \\
(9.1)\end{array}$ & $\begin{array}{l}A B 0 \\
(0.0)\end{array}$ & $\begin{array}{l}\mathrm{ABO} \\
(0.0)\end{array}$ & $\begin{array}{c}A B 7 \\
(63.6)\end{array}$ \\
\hline Age $>55+F C P>100(n=42)$ & $\begin{array}{l}\text { AB22 } \\
(52.3)\end{array}$ & $\begin{array}{l}\mathrm{AB} 2 \\
(4.8)\end{array}$ & $\begin{array}{l}\mathrm{ABO} \\
(0.0)\end{array}$ & $\begin{array}{l}\mathrm{AB} 0 \\
(0.0)\end{array}$ & $\begin{array}{l}\mathrm{AB} 2 \\
(4.8)\end{array}$ & $\begin{array}{l}\mathrm{AB} 2 \\
(4.8)\end{array}$ & $\begin{array}{l}\mathrm{AB} 0 \\
(0.0)\end{array}$ & $\begin{array}{l}\mathrm{AB} 2 \\
(4.8)\end{array}$ & $\begin{array}{l}\mathrm{AB} 12 \\
(28.5)\end{array}$ \\
\hline
\end{tabular}

reviewed in addition to clinic letters to understand clinician interpretation of results when necessary. Patients were categorised by age and FCP result. Outcomes in patients without IBD were categorised as: new IBD, non-specific inflammation/ulceration (NSI), peptic ulcer disease (PUD), cancer, colorectal adenoma (CRA), coeliac disease, other (including irritable bowel syndrome, bile salt malabsorption) or unknown where no additional information was available.

Results 147 positive (of 391, 37.6\%) FCP results were identified. 11 were excluded, as investigations were ongoing. The outcome of investigations per category are summarised in Table 1.

Conclusion The use of FCP is increasing. In our unit, the majority are used for assessment in patients with known IBD. In patients in whom FCP was used to aid diagnosis, those with a result $<100$ had a 'benign' diagnosis following investigation in both age categories suggesting a considered approach in this group may be reasonable.

Disclosure of Interest None Declared.

\section{PTH-162 THE CHALLENGES OF IMPLEMENTING EVIDENCE INTO ENDOSCOPIC PRACTICE: A QUALITATIVE STUDY}

doi:10.1136/gutjnl-2013-304907.649

1."P T Rajasekhar, ${ }^{2} \mathrm{~S}$ Brown, ${ }^{3} \mathrm{C}$ Nixon, ${ }^{4} \mathrm{M}$ Bramble, $5 \mathrm{~J}$ East, ${ }^{6} \mathrm{M}$ Rutter, ${ }^{7} \mathrm{~B}$ Saunders, ${ }^{1} \mathrm{C}$ Rees on behalf of The Quality in Colonoscopy Study Group. 'Gastroenterology, South Tyneside District Hospital, South Shields; '2Evaluation Research Development Unit, Durham University, Stockton-on-Tees; ${ }^{3}$ Department of Social Science, Sunderland University, Sunderland; ${ }^{4}$ School of Medicine and Health Science, Durham University, Stockton-on-Tees; ${ }^{5}$ Gastroenterology, John Radcliffe Hospital, Oxford; ${ }^{6}$ Gastroenterology, University Hospital of North Tees, Stockton-on-Tees; ' Gastroenterology, St Marks Hospital, Harrow, UK

Introduction The Quality Improvement in Colonoscopy (OIC) study was a region wide service improvement study that aimed to improve adenoma detection rate (ADR), and thusly quality in colonoscopy, through implementation of a 'bundle' of measures to routine colonoscopy practise. These were: withdrawal time $\geq 6$ minutes; routine hyoscine butylbromide use; supine position to examine the transverse colon; rectal retroflexion. Each has been shown to improve adenoma detection. The implementation of evidence into clinical practise can be challenging. We performed a qualitative interview study to evaluate factors that influenced implementation of the 'bundle' in the OIC study.

Methods The study took place in 12 units who are members of the Northern Region Endoscopy Group, a research network in the north east of England. The study team held training sessions in each unit to introduce the 'bundle', supported by a nominated local lead colonoscopist and nurse. Posters were supplied for each endoscopy room to aid promotion. Following OIC study completion units and individuals were purposively sampled for the qualitative interview study ensuring a range of units (by size, bundle uptake) were included. Semi-structured interviews were conducted until saturation was reached. Data were evaluated using thematic analysis to code and categorise interviews.
Results 119 colonoscopists participated in the OIC study. Interviews were conducted with 11 participants. 8 were lead colonoscopists, 1 a lead nurse and 3 colonoscopists who weren't leads. Increased emphasis on examination time, increased awareness of $\mathrm{ADR}$ as a quality marker and empowerment of endoscopy nurses to encourage use of quality measures were seen as positive impacts of introducing the 'bundle'. The simple, highly visible posters were also reported as useful in aiding study promotion. Challenges included difficulty in arranging set up meetings and in engaging certain speciality groups.

Conclusion Implementation of evidence into clinical practise can be challenging. During the OIC study, challenges included arranging staff meetings and engaging all team members. Positive outcomes included increased awareness of colonoscopy quality, particularly slower withdrawal times, and empowerment of endoscopy nurses to promote quality measures. We demonstrate that emphasis on timing of meetings and strategies to engage speciality groups should be given consideration when planning implementation of evidence or guidelines into clinical practise.

Disclosure of Interest None Declared.

\section{PTH-163 NURSE LED TELEPHONE CLINICS- THE NHS REVOLUTION IN MAKING}

doi:10.1136/qutinl-2013-304907.650

1."R Shah, ${ }^{2} \mathrm{~L} T$ Tan, ${ }^{3} \mathrm{G}$ Lim. ${ }^{1}$ Gastroenterology, NHS, Farnborough; ${ }^{2}$ Gastroenterology; ${ }^{3}$ NHS, Epsom, UK

Introduction Patients under the care of Gastroenterologists suffer from a wide variety of acute and chronic conditions which often need regular intensive monitoring. This often necessitates frequent outpatient visits and follows up blood tests.

To improve both patient care and efficiency, a telephone clinic led by nurse specialists was instigated.

The patients included those with follow ups of investigations into anaemia, abnormal liver function tests, coeliac disease, inflammatory bowel disease hepatitis $\mathrm{B} / \mathrm{C}$ and irritable bowel disease.

Patients, who required drug monitoring, follow up of blood tests, histology and radiological investigations including flare ups of their inflammatory bowel condition were included.

Methods This initial consultation was in a consultant led clinic following which the results were communicated via the telephone clinic in 4-6 weeks. Depending on the initial results further investigations, treatment or follow up was arranged according to clinical need.

Patients with flares of IBD, follow up of treatment of Hepatitis $\mathrm{B} / \mathrm{C}$ were now directly in contact with nurse led telephone clinics who in turn could give specialist advise and expedite treatment and investigations.

December 2009 were analysed. Similar data from 2005 was used as control ${ }^{\text {st }}$ January 2009 to $31^{\text {st }}$ Data regarding outpatient and telephone clinic activities from 1 . 